\title{
Development of technology for a long-term monitoring and automatic data acquisition system
}

\author{
*Akira Shidai ${ }^{1}$, Kenzo Kiho" ${ }^{1}$, Yasuji Saito ${ }^{2}$, and Tomohiro Kawakami ${ }^{3}$ \\ ${ }^{I}$ Central Research Institute of Electric Power Industry (CRIEPI), Chiba, Japan \\ ${ }^{2}$ Tokyo Electric Power Services Co., Ltd. (TEPSCO), Tokyo, Japan \\ ${ }^{3}$ Toyo Electric Co., Aichi, Japan \\ *Corresponding author: shidai@tepsco.co.jp
}

\begin{abstract}
The Central Research Institute of Electric Power Industry conducted research to develop a long-term monitoring technology to clarify pore water pressure and water chemistry in drilled boreholes. An automatic data acquisition system for the long-term monitoring was also developed. The automatic data acquisition system has an independent electric power supply and data communication system. The electric power is supplied from solar and wind power. The data communication is secured through a satellite or $3 \mathrm{G} / 4 \mathrm{G}$ line. A very low power consumption system can be readily installed by creating personal area networks between measuring devices using Zigbee digital radio. A demonstration of the system was conducted under harsh natural conditions for 18 months. It was confirmed that the system has sufficient reliability for actual operation.
\end{abstract}

Keywords: Monitoring, Wireless, Zigbee

Paper Received: 30 Jan 2018

Paper Accepted: 17 March 2018

\section{INTRODUCTION}

High-level radioactive waste (HLW) is planned to be geologically disposed in Japan. Disposal sites will be selected via three stages of investigation. A literature survey will be conducted first followed by a preliminary investigation during the next stage. Constructing underground survey facilities, a detailed investigation will be conducted during the third stage. The construction of the underground survey facilities or the final depository might affect geological, environmental, and radiological conditions. It is very important to evaluate these effects by obtaining the pore water pressure and water chemistry baseline conditions through long-term monitoring of boreholes during the preliminary investigation (Kurikami et al., 2010).

It is assumed that the investigation for the HLW disposal site selection will be conducted in a wide area without electricity and communication infrastructure. To conduct long-term monitoring under such conditions, it is assumed that a system by which investigators can monitor various environmental characteristics remotely would be needed.

The purpose of this study was to develop a long-term monitoring technology to determine pore water pressure and water chemistry in a drilled borehole and an automatic data acquisition system for use in long-term monitoring.

\section{DEVELOPMENT OF LONG-TERM MONITORING TECHNOLOGIES}

The Central Research Institute of Electric Power Industry (CRIEPI) has been conducting a project to develop directional drilling and measurement/logging technologies to survey hydrogeological conditions as part of the investigation supporting HLW disposal site selection (Kiho et al., 2014). A 1000-m-long borehole, termed HCD-3, was drilled by directional drilling technology to verify the drilling technology. The HCD-3 site is at Kami-horonobe, Horonobe, Hokkaido (Fig. 1). The geology surrounding the drilling site is mainly composed of the Koetoi and the Wakkanai formations of the Neogene period of the Tertiary. The directional drilling trajectory is shown in Fig. 2.

For soft sedimentary rocks, a casing pipe protects the borehole wall and the annulus is filled with cement. The casing pipe has to be perforated such that the pore water pressure measurement sections can be established by installing packers in the casing pipe. Then, the monitoring devices are set in the perforated casing such that measuring can begin. The method is a general measuring method for long-term monitoring of pore

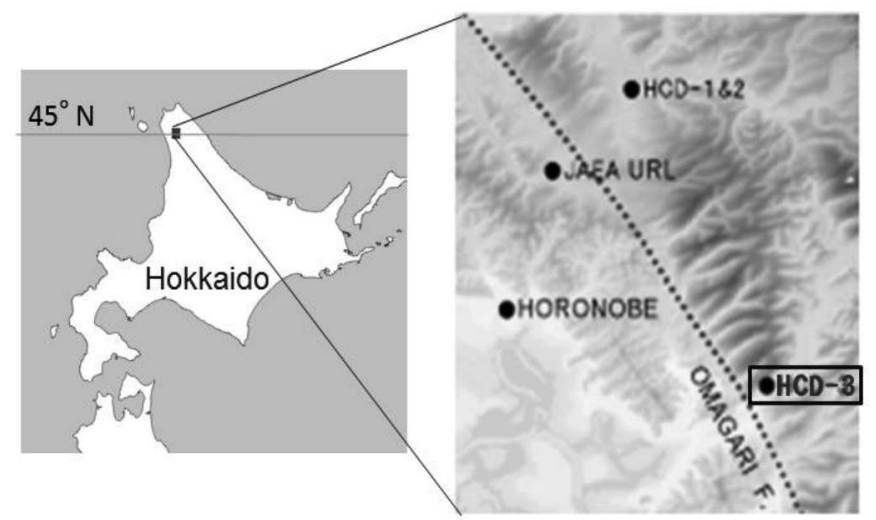

Fig. 1: Location of the demonstration site (HCD-3) 


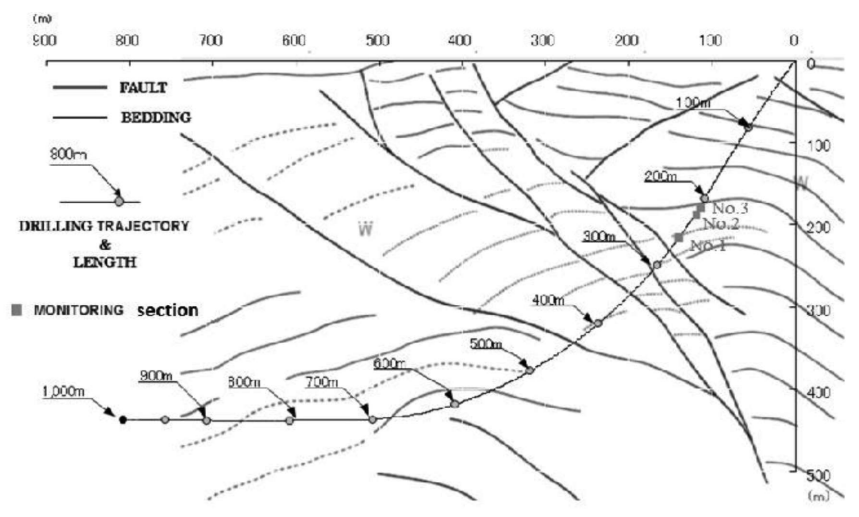

Fig. 2: Directional drilling trajectory and monitoring sections

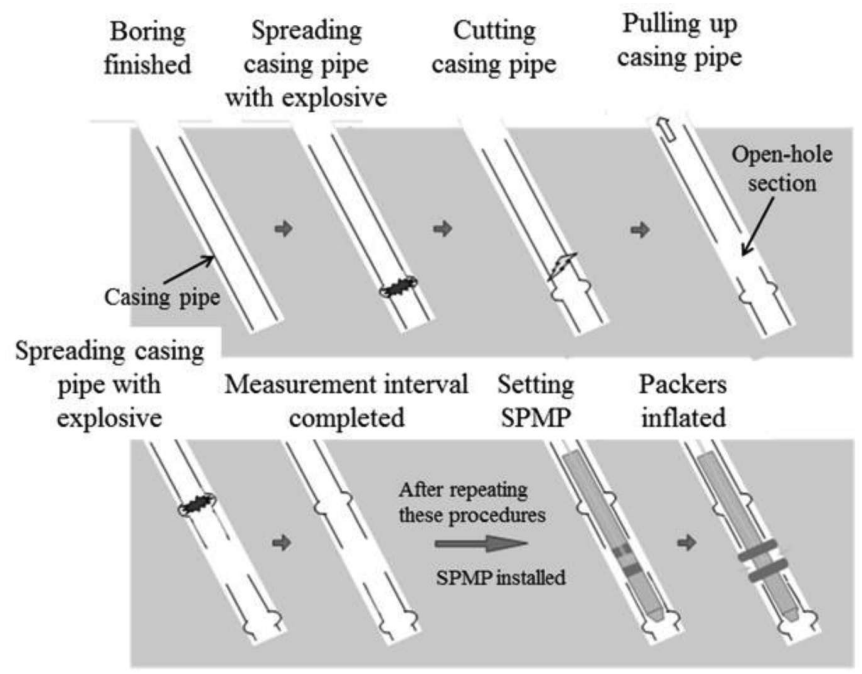

water pressure in soft sedimentary rocks (JAEA URL, 2003).

In this study, pore water pressure and water chemistry were monitored. It was assumed that the cementitious material in the annulus might affect water chemistry when using a general measuring method. Given this, open-hole measurement sections were constructed by newly developed procedures as shown in Fig. 3.

The Standpipe Multi Packer (SPMP) system was developed as another method for measuring pore water pressure of boreholes (Kiho et al., 2011). The outline of SPMP applied to HCD-3 is shown in Table 1 and Fig. 4. In this system, packers are set directly on the open-hole wall, and water that is not affected by the annulus can be sampled from the standpipe. The SPMP, which is easy to maintain during the monitoring, has been proven to perform satisfactorily for an inclined borehole.

Table 1: Outline of SPMP

\begin{tabular}{ll}
\hline System & Standpipe Multi Packer System (SPMP) \\
Measurement Sections & 5 sections (maximum) \\
Diameter of Devices & Casing : $76.1 \mathrm{~mm} / 70.9 \mathrm{~mm}$ (outer/inner) \\
& Packer : $180 \mathrm{~mm} / 110 \mathrm{~mm}$ (inflation/deflation) \\
& Standpipe: $23 \mathrm{~mm} / 21 \mathrm{~mm}$ (outer/inner) \\
& Number of standpipes: 5 (maximum) \\
& Sensor technology: Piezo-resistive \\
Pressure Gauge & Working pressure range: $0-10 \times 10^{5} \mathrm{~Pa}$ \\
(for pore water pressure) & Linearity: $0.025 \% \mathrm{FS}$, Resolution: $0.002 \% \mathrm{FS}$ \\
& Size: $\varphi 16 \mathrm{~mm}$, length 120 mm \\
& Pore water pressure \\
Measurement Items & In situ groundwater chemistry by sampling \\
\hline
\end{tabular}

Fig. 3: Spreading, cutting, and pulling up casing pipe method

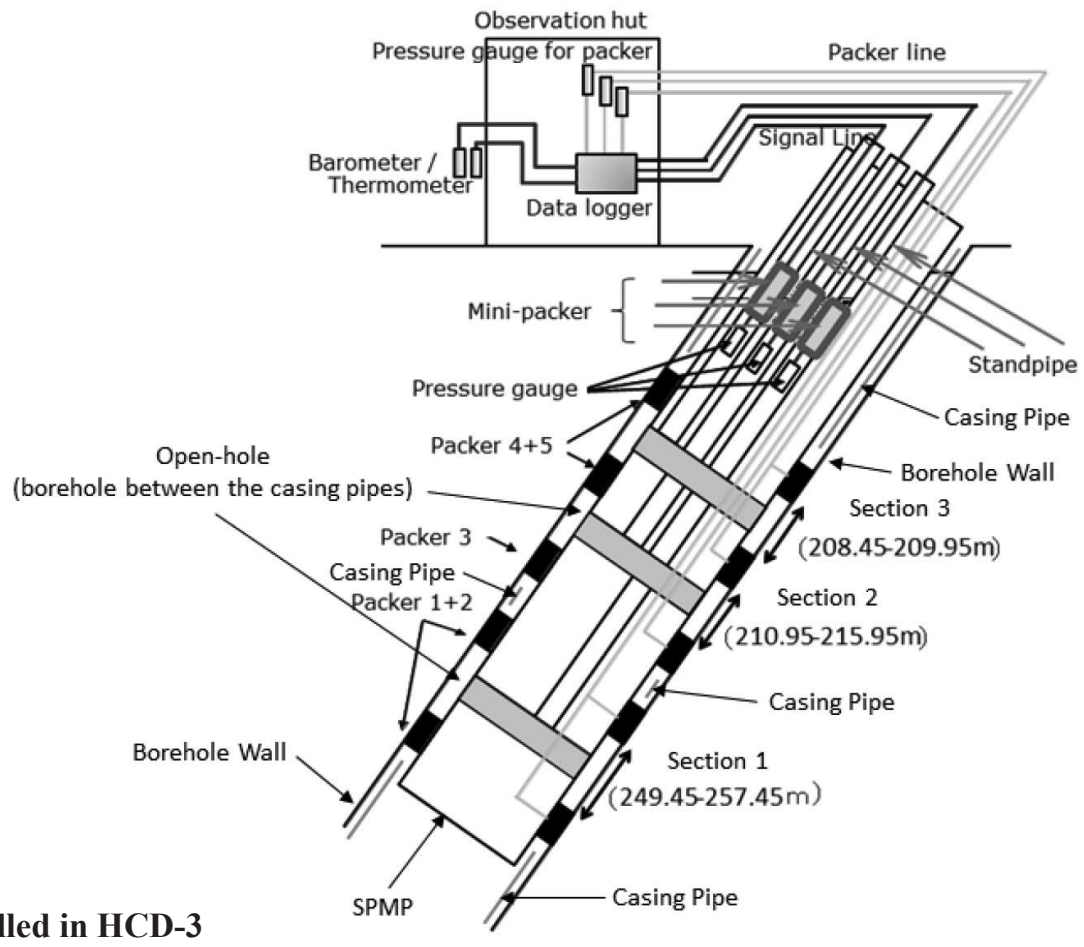

Fig. 4: SPMP installed in HCD-3 


\section{DEVELOPMENT OF AN AUTOMATIC DATA ACQUISITION SYSTEM}

During HLW disposal site selection, long-term monitoring of several boreholes will be conducted to estimate the initial geological/environmental conditions. Measurements will be recorded in large areas far from cities or towns, where power supply and/or communication networks are less available.

Based on plant data, an automatic data acquisition system for long-term monitoring, the wireless collection and monitoring system Advanced Topological on-demand Monitoring System ATOMS, was developed. ATOMS, which has various reliable records of nuclear power plants for radiation monitoring, has an independent power supply at each monitoring station and performs local data communication based on a wireless network using Zigbee digital radio (Fig. 5).

There is no electricity at the HCD-3 site. During winter, the temperature drops to nearly minus 30 degrees Celsius and the site is covered with snow to a depth of more than one meter. There are over 30 items to be measured. Thus, it is difficult to reach the site and conduct measurements during the winter. Considering these conditions, an automatic data acquisition system for long-term monitoring was designed and installed at the HCD-3 site (Shidai et al., 2016). A configuration diagram and photograph of the system are shown in Fig. 6. Requirements for the equipment of the system are shown in Table 2 .

A hybrid power supply system was adopted. The power is supplied from solar and wind power. Excess electricity is stored in a battery. Data communication is secured via satellite and $3 \mathrm{G} / 4 \mathrm{G}$ lines. The system does not require troublesome wiring. Pore water pressure in the drilled borehole, surrounding environmental data, and the state of the measuring equipment can be monitored remotely using the system. Real-time consecutive monitoring is possible by remote control at the time of a critical natural event such as a large earthquake.

A function block diagram of the system is shown in Fig. 7. Each sensor measures pore water pressure, packer pressure, temperature, barometric pressure, solar radiation, power consumption, etc., every minute. All measurement data are accumulated in a network computer (NC) using local wireless communication. The data logger Magic Bee (MGB) is a key device that supports the low power consumption system and plays a role in the slave station of local communication (Fig. 8). MGB is equipped with wireless communication standard Zigbee. The power consumption of Zigbee is $10 \%$ of that of Bluetooth. Measurement data are stored in the NC and a micro secure digital (SD) card incorporated in the MGB for data backup. The system at HCD-3 has nine MGBs. The stored data in the NC are sent to a web server via satellite or $3 \mathrm{G} / 4 \mathrm{G}$ line, hourly.

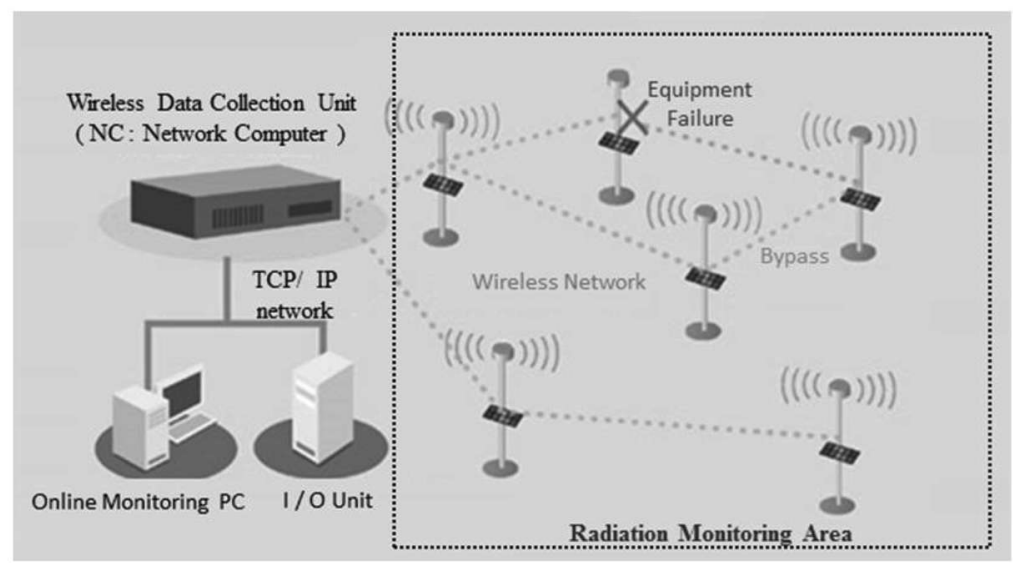

Fig. 5: Outline of ATOMS and radiation monitoring station

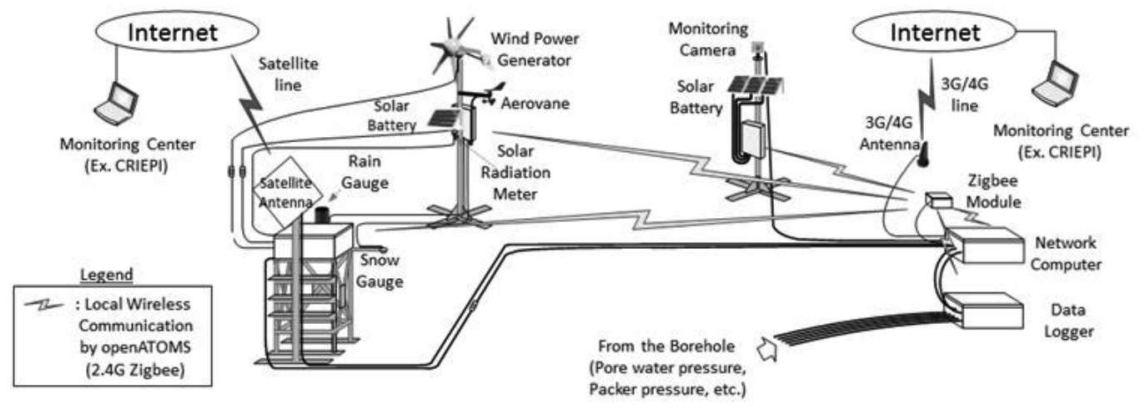

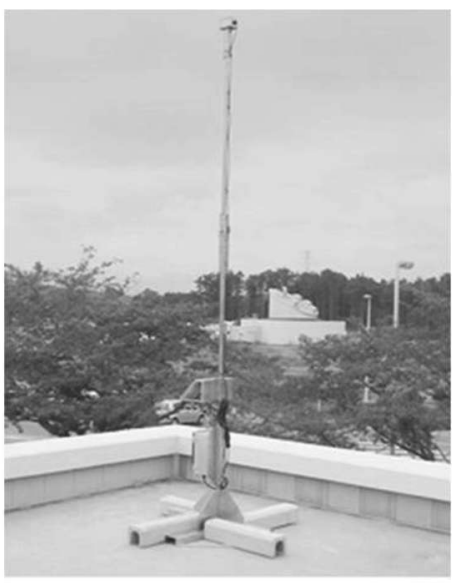

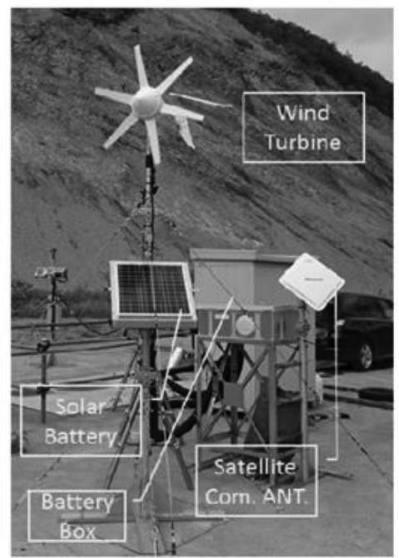

Fig. 6: Configuration diagram and photograph of the automatic data acquisition system for HCD-3 
Table 2: Equipment of the automatic data acquisition system at HCD-3

\begin{tabular}{|c|c|c|}
\hline EQUIPMENT & REQUIREMENTS & $\begin{array}{l}\text { PRODUCT MODEL } \\
\text { (Manufacturer) }\end{array}$ \\
\hline Network Computer & $\begin{array}{l}\text { - Stability as host device driver and control unit device } \\
\text { - Low power consumption } \\
\text { - System extensibility for multiple survey points } \\
\text { - Flexible customization capabilities }\end{array}$ & $\begin{array}{l}\text { openATOMS } \\
\text { (SHIKOKU RESEARCH INSTITUTE) }\end{array}$ \\
\hline Data Loggers & $\begin{array}{l}\text { - Low power consumption } \\
\text { - Control of the operation modes } \\
\text { - Correspondence to the number of measurement points }\end{array}$ & $\begin{array}{l}\text { MAGIC BEE } \\
\text { (TOYO ELECTRIC) }\end{array}$ \\
\hline Satellite communications equipment & $\begin{array}{l}\text { - Stable communication } \\
\text { - Low power consumption }\end{array}$ & $\begin{array}{l}\text { NTT DOCOMO Widestar II } \\
\text { (MUTSUBISHI ELECTRIC) }\end{array}$ \\
\hline Communication satellite antenna & - Compatibility to the satellite communication equipment & $\begin{array}{l}\text { AAD68096 } \\
\text { (MUTSUBISHI ELECTRIC) }\end{array}$ \\
\hline Mobile router & $\begin{array}{l}\text { - Environmental capability for severe weather condition } \\
\text { - General purpose router for } 3 \mathrm{G} / 4 \mathrm{G} \text { communication }\end{array}$ & $\begin{array}{l}\text { HSPA-450C } \\
\text { (GENETEC) }\end{array}$ \\
\hline Surveillance camera & $\begin{array}{l}\text { - Stability for severe weather condition } \\
\text { - General purpose camera for surveillance }\end{array}$ & $\begin{array}{l}\text { BB-SW175A } \\
\text { (PANASONIC) }\end{array}$ \\
\hline Wind turbine & $\begin{array}{l}\text { - Power generation capacity required for the system } \\
\text { - Stability for severe weather condition }\end{array}$ & $\begin{array}{l}\text { WTR-91012 12V } \\
\text { Diameter of Rotor: } 910 \mathrm{~mm} \\
\text { Rated output: } 72 \mathrm{~W}(10 \mathrm{~m} / \mathrm{sec}) \\
\text { (MARLEC) }\end{array}$ \\
\hline Solar battery & $\begin{array}{l}\text { - Power generation capacity required for the system } \\
\text { - Stability for severe weather condition }\end{array}$ & $\begin{array}{l}\text { KC- } 32 \mathrm{~T}-02 \\
\text { Size: } 517 \times 512 \mathrm{~mm} \\
\text { Rated output: } 32 \mathrm{~W} \\
\text { (KYOCERA) }\end{array}$ \\
\hline Battery & $\begin{array}{l}\text { - Storage capacity } \\
\text { - Stability for severe weather condition }\end{array}$ & $\begin{array}{l}\text { SEB- } 50 \\
\text { Storage capacity: } 12 \mathrm{~V} 50 \mathrm{Ah} \\
\text { (GS YUASA) }\end{array}$ \\
\hline
\end{tabular}
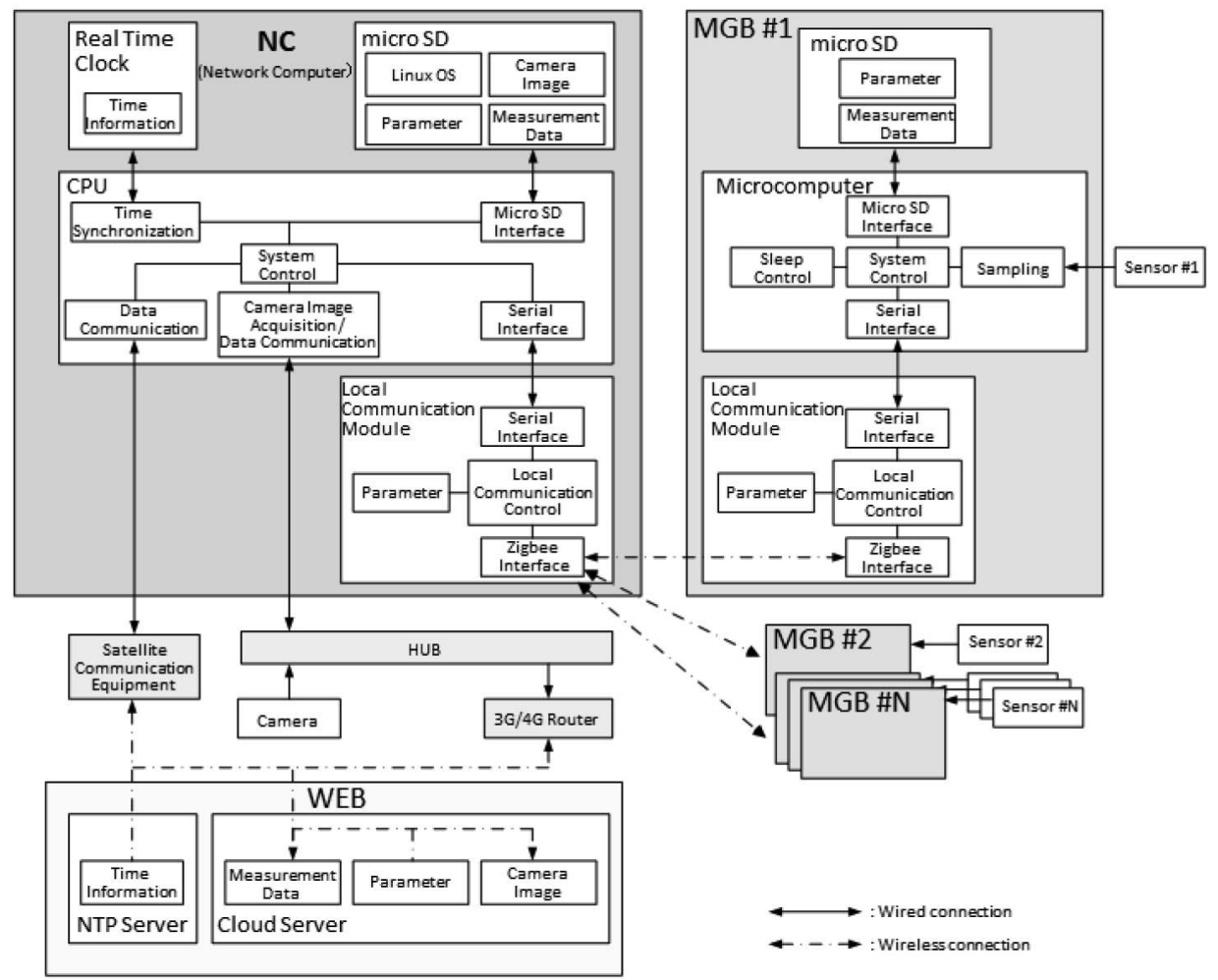

Fig. 7: Function block diagram of the system 


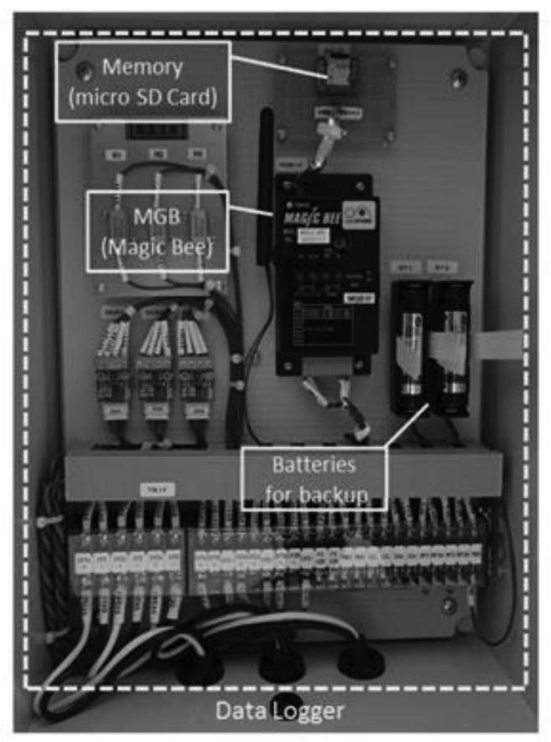

Fig. 8: Data logger box with MGB

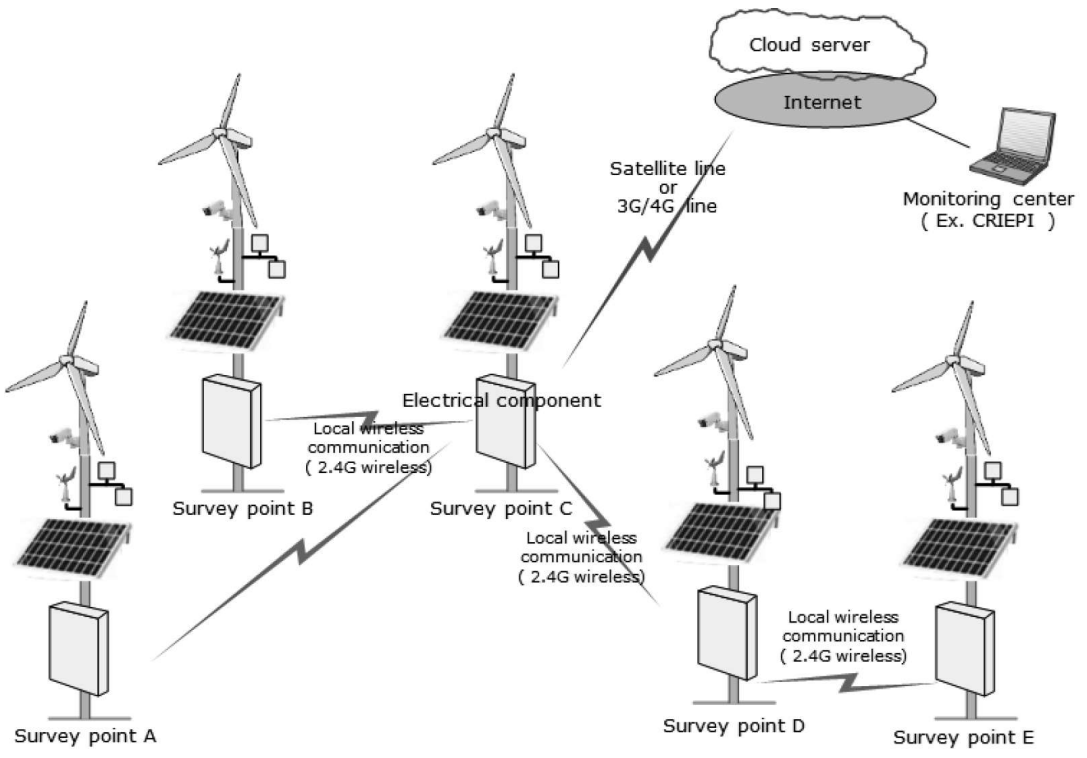

Fig. 9: Simultaneous monitoring system for multiple survey points
The system installed at HCD-3 is a stand-alone data acquisition system; however, simultaneous monitoring is also possible by creating a local wireless network for each borehole in a preliminary investigation area such as one with less sunlight and without adequate power supply and communication network infrastructure. In the case of measuring or monitoring multiple survey points, the system can be changed to an adaptable system by installing a stand-alone data acquisition system at each survey point and connecting each with 2.4-GHz wireless Zigbee digital radios (Fig. 9).

\section{MEASUREMENT RESULTS OF PORE WATER PRESSURE IN A BOREHOLE}

The SPMP was installed in HCD-3 during February 2014. The pore water pressure of three sections was measured until early May 2017. An automatic data acquisition system for long-term monitoring was installed during October 2015. Fig.
10 shows the measurement results of pore water pressure in HCD-3. The pore water pressure was measured using a stand pipe, thus the water pressure is indicated by water head as shown in the figure.

Section 3 shows higher values than those of section 1 and section 2. Section 3 has long-term data loss due to the instability of the water sampling pressure for water quality measurement. Section 2 also has long-term data loss due to mini packer malfunction. At the beginning of the introduction of the automatic data acquisition system, intermittent data loss occurred due to a system malfunction.

\section{RELIABILITY OF THE AUTOMATIC DATA ACQUISITION SYSTEM}

While adjusting the automatic data acquisition system equipment, the system operated for 18 months. Fig. 11 shows the transfer rate of data to a web server on the internet for each

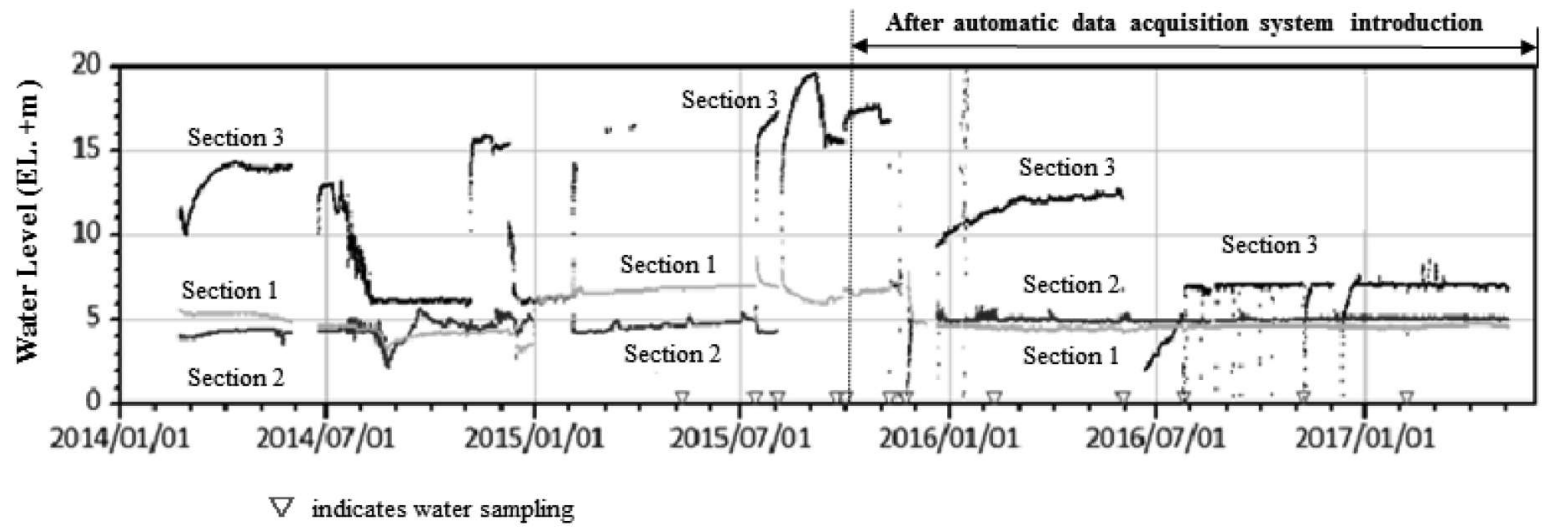

Fig. 10: Measurement results of pore water pressure in HCD-3 


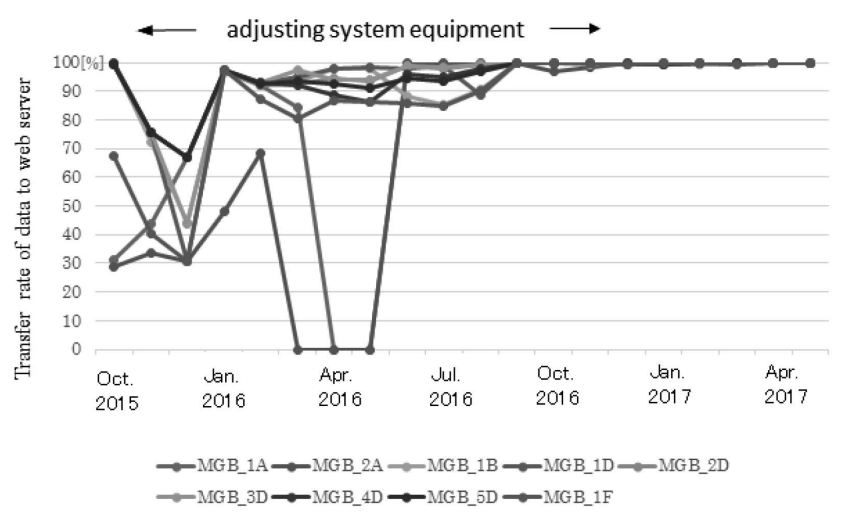

Fig. 11: Data transfer rate to web server on the internet

MGB. There were some data transmission failures during the beginning of system introduction; however, data that had not been sent by internet were stored in the NC and micro SD for backup. Nearly $100 \%$ of the data were sent to the web server after adjusting the system equipment (Shidai et al., 2017).

\section{CONCLUSION}

As a result of field application of long-term monitoring technology developed for HLW disposal site selection, it has been demonstrated that pore water pressure behavior in a borehole can be continuously measured. This technology will be a useful tool for evaluating pore water pressure baseline.

It was confirmed that the automatic data collection system developed together with the long-term monitoring technology had sufficient reliability for actual operation under harsh environmental conditions.

\section{ACKNOWLEDGEMENTS}

The research and development of this study were funded by the Agency for Natural Resources and Energy, an external bureau of the Ministry of Economy, Trade and Industry. The long-term monitoring was conducted as a collaboration with the Horonobe Underground Research Center of Japan Atomic Energy Agency. The authors gratefully acknowledge their cooperation.

\section{REFERENCES}

JAEA URL (Horonobe Underground Research Center of Japan Atomic Energy Agency) (formerly the Japan Nuclear Cycle Development Institute), 2003, "General report of a research project at Horonobe," (written in Japanese).

Kiho, K., Obuchi, Y., Miyakawa, K., Sunaga, T., and Matsumura, S., 2011, "Development of drilling technique for the hydrogeological survey-Outline of monitoring system and system setup", Proceedings of the Japan Society of Engineering Geology, pp. 119-120, (written in Japanese with English title).

Kiho, K., Miyakawa, K., and Suenaga, H., 2014, "Development of Directional Drilling and Survey System, -Results of the Drilling and In-situ Permeability Test," Proceedings of the 8th Asian Rock Mechanics Symposium, RW2-6.

Kurikami, H., Takahashi, Y., Yoshizawa, Y., Miwa, T., Akamura, S., and Kawano, K., 2010, "Study on monitoring and primary baseline for geological disposal of radioactive waste," Technical report published by the Nuclear Waste Management Organization of Japan (NUMO), NUMOTR-10-01, (written in Japanese with English abstract).

Shidai, A., Kiho, K., and Murata, M., 2016, "Directional Drilling Technology for HLW Disposal - Long Term Monitoring in the Borehole -," Waste Management Symposia 2016, 16079 .

Shidai, A., Kiho, K., Saito, Y., and Kawakami, T., 2017, "Development on automatic measurement system for long-term monitoring (No. 3) - Targeting systematization of monitoring technology", Proceedings of the Japan Society of Engineering Geology, pp. 223-224, (written in Japanese with English title). 